Article

\title{
Predicting Compressive Strength of Cement-Stabilized Rammed Earth Based on SEM Images Using Computer Vision and Deep Learning
}

\author{
Piotr Narloch ${ }^{1, *(\mathbb{D})}$, Ahmad Hassanat ${ }^{2,3}$ (), Ahmad S. Tarawneh ${ }^{4}$, Hubert Anysz ${ }^{1, *(D)}$, \\ Jakub Kotowski ${ }^{5}$ (i) and Khalid Almohammadi ${ }^{3}$ \\ 1 Faculty of Civil Engineering, Warsaw University of Technology, Al. Armii Ludowej 16, 00-637 Warsaw, \\ Poland \\ 2 Computer Science Department, Mutah University, 61710 Karak, Jordan; hasanat@mutah.edu.jo \\ 3 Computer Science Department, Community College, University of Tabuk, 71941 Tabuk, Saudi Arabia; \\ kalmohammadi@ut.edu.sa \\ 4 Department of Algorithms and Their Applications, Eötvös Loránd University, 1053 Budapest, Egvetem ter \\ 1-3 Hungary; Ahmad.trwh@gmail.com \\ 5 Faculty of Geology, University of Warsaw, Żwirki i Wigury 93, 02-089 Warsaw, Poland; j.kotowski@uw.edu.pl \\ * Correspondence: p.narloch@il.pw.edu.pl (P.N.); h.anysz@il.pw.edu.pl (H.A.); Tel.: +48-691-660-184 (P.N.); \\ $+48-606-668-288$ (H.A.)
}

Received: 1 October 2019; Accepted: 22 November 2019; Published: 27 November 2019

check for updates

\begin{abstract}
Predicting the compressive strength of cement-stabilized rammed earth (CSRE) using current testing machines is time-consuming and costly and may harm the environment due to the samples' waste. This paper presents an automatic method using computer vision and deep learning to solve the problem. For this purpose, a deep convolutional neural network (DCNN) model is proposed, which was evaluated on a new in-house scanning electron microscope (SEM) image database containing 4284 images of materials with different compressive strengths. The experimental results show reasonable prediction results compared to other traditional methods, achieving $84 \%$ prediction accuracy and a small (1.5) oot Mean Square Error (RMSE). This indicates that the proposed method (with some enhancements) can be used in practice for predicting the compressive strength of CSRE samples.
\end{abstract}

Keywords: deep learning; convolutional neural network; SEM images; rammed earth; cement-stabilized rammed earth; cement stabilization

\section{Introduction}

\subsection{Aim and Scope of the Research}

This article aims to present that machine learning can predict the compressive strength of building materials with a high degree of accuracy based on scanning electron microscope (SEM) images. The methodology of predicting the compressive strength of cement-stabilized rammed earth (CSRE) is described and the results achieved

CSRE is a material used to build construction walls from locally available, inorganic soil found under the layer of humus. Most importantly, CSRE is a highly sustainable construction material. In the study [1], resulting from an analysis using the Building Research Establishment Environmental Assessment Method (BREEAM), external building partitions containing a load-bearing rammed earth layer obtained the highest A+ rating. According to Hall and Swaney [2], such a rating would also be obtained by a partition with a load-bearing layer of rammed earth stabilized with cement. However, 
designing CSRE of sufficiently high compressive strength is difficult because this feature depends on several mixture properties and technological issues, such as a compaction method [3], density of elements [4-6], porosity of elements [6], particle size distribution of the soil [4,5,7], mineral composition of the soil [8], content and type of cement used as a stabilizer [6,9,10], moisture content of the soil-cement mixture during construction [4,9,11-13], moisture content of element during service [11,12], exposure conditions of the construction elements $[5,14]$, and age of the construction elements $[6,15,16]$.

A multitude of factors hampers the practical application of rammed earth technology. Even if a method of predicting the compressive strength of CSRE based on these factors is developed, assembling a structure using locally sourced soil would require detailed laboratory tests on a case-by-case basis, to determine the basic parameters of that soil-e.g the mineral composition and particle size distribution of the soil. Other properties of the soil-cement mixture, such as the moisture content, may change unexpectedly due to changes in atmospheric conditions prevailing at the construction site. It is proposed to model the compressive strength of CSRE partitions based on SEM images using machine learning and deep learning techniques instead of the whole process involving laboratory testing and the creation of models of relationships between mixture properties and parameters. The proposed method is presented in the article.

\subsection{Method of Erecting Monolithic CSRE Walls}

The method of erecting monolithic CSRE walls (see Figure 1) includes the following stages [17,18]:

- Laying concrete foundations and assembling on them a formwork for the designed CSRE walls.

- Preparing the soil-cement mixture. I If necessary, the particle size composition of the locally available soil is adjusted. Next, Portland cement is added. The components are mixed in an air-dry state until they reach a uniform consistency. Just before the planned ramming, water is added in a quantity that gives the mixture its predetermined optimal moisture content.

- $\quad$ Ramming the moist soil mixture in the formwork in layers. Obtaining the required compaction depends on the method of ramming, energy used for the compaction process, and the thickness of the CSRE layer. The effectiveness of the compaction process should be verified experimentally under construction conditions.

- Curing of the finished wall in the formwork for a minimum of one day, followed by demolding.

Further curing of the wall after demolding should be continued until obtaining full serviceable properties by CSRE structure., The minimum curing time is 28 days in the air temperatures above $0{ }^{\circ} \mathrm{C}$ (Celsius scale). During this period, it is recommended to cover the partition against precipitation and excessive sun exposure. 


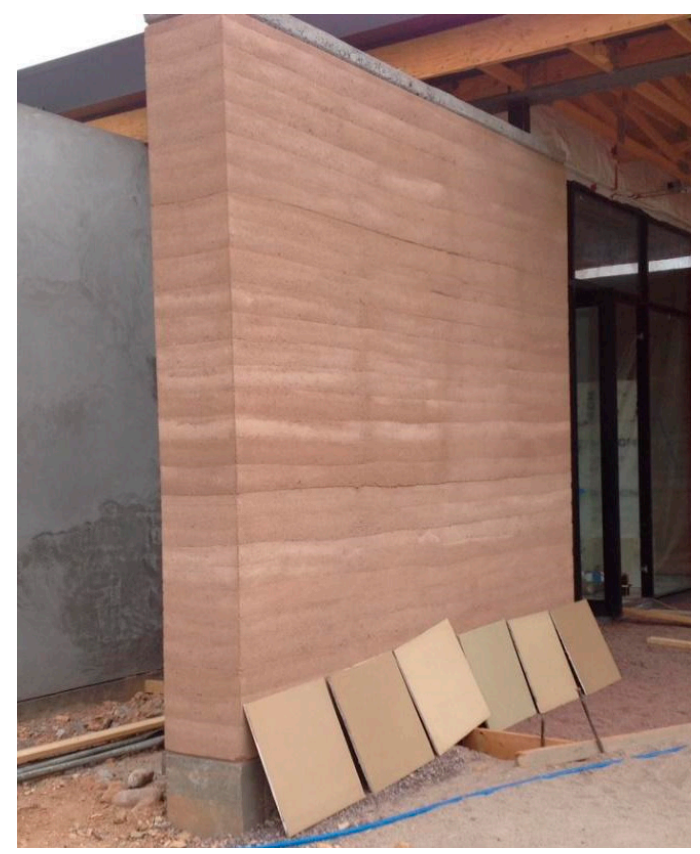

Figure 1. Wall made from compacted earth. The compacted layers of mixed soil are shown.

\section{Related Work}

It was found that various machine learning techniques were used to predict the state of various materials' features based on SEM images of these materials. Lahoti et al. used machine learning-based classifiers and statistical analyses to predict the compressive strength of metakaolin-based geopolymers. They applied random forests; Naive Bayes, and the k-nearest neighbors classifiers, while the statistical analysis was based on an analysis of variance (ANOVA) [19].

The prediction of the compressive strength of concrete modified with glass cullet was conducted by Mirzahosseini and co-workers [20], who used genetic programming to build the prediction models of the compressive strength. Their sensitivity and parametric analyses confirmed that the compressive strength is very sensitive to curing time and temperature, as well as to the surface area of the particles.

Qin et. al. employed a deep learning technique to establish an end-to-end mapping of the nonlinear relationship between SEM images of the cemented paste backfill and its mechanical strengths. However, the average accuracy of the prediction of the mechanical strength was very low [21]. There more examples of this approach e.g. [22,23].

Perhaps the most related study to this paper is the work of Gallagher and co-workers [24], which explores the application of computer vision and machine learning methods to predict the compressive strength of consolidated molecular solid (triaminotrinitrobenzene (TATB)) samples based on their SEM images. However, the TATB samples are not as complex as the CSRE ones, and therefore the reported results may not be able to be generalized to the CSRE, the core of this paper.

The deep learning techniques allow for a wide range of their applications and better solutions for many problems in the computer vision domain, as shown by [25-35], and others. All of these works recommend the use of deep learning techniques to find better solutions in the area of computer optics, in the computer vision domain, which is the main motivation for using the deep learning technique in this paper.

To the best of the authors' knowledge, this work is the first attempt to the problem of predicting the compressive strength of CSRE based on SEM images using computer vision and deep learning. The main contribution of this paper is twofold. It proposes a new deep learning approach to solve the research problem; secondly, it describes a new SEM image database of the CSRE samples, which was created for this study. 


\section{Materials and Methods}

\subsection{Materials}

Through adding the appropriate amount of dry ingredients (seven types of loams with different mineral compositions, as well as sand of pure quartz and gravel of $75 \%$ quartz and carbonate crumbs), seven artificial soils with two different particle size distributions labeled LC and MC (LC with $4 \%$ and MC with $16 \%$ of clay fraction, see Figure 2 ) were obtained. These artificial soil mixtures simulated the inorganic soils with different mineral compositions that could be obtained locally in Europe and were used as the main component of CSRE. Then, cement CEM I 42.R was added in an amount of $6 \%$ or $9 \%$ by weight of the artificial soil. Finally, water was added to dry mixtures to obtain optimum moisture content (OMC). The compositions of all 14 mixtures are shown in Table 1.

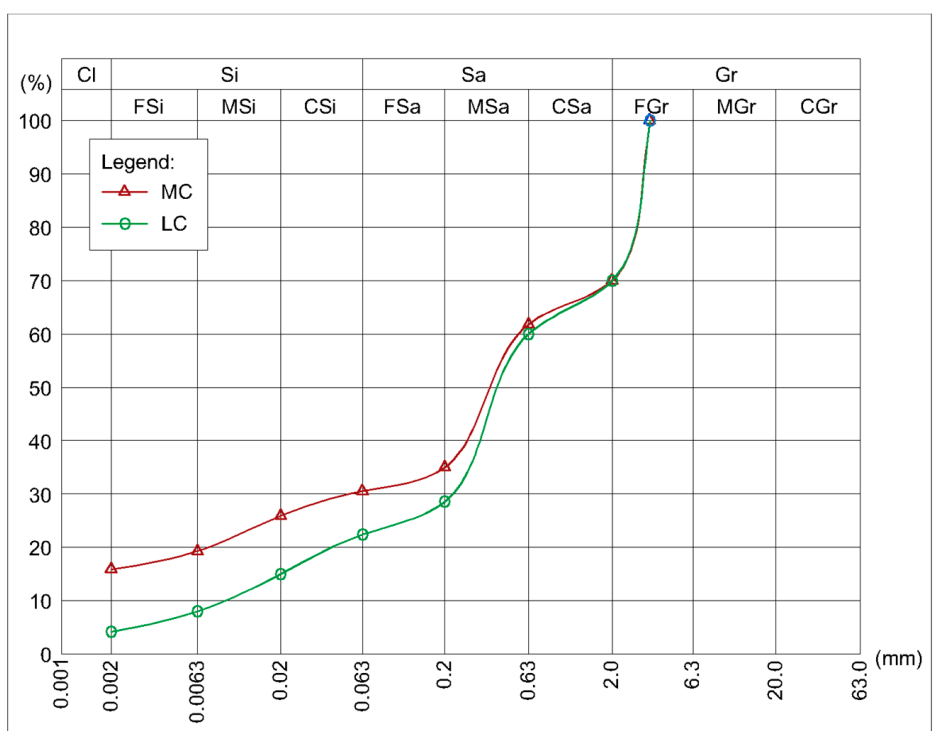

Figure 2. The particle size distribution of soil mixtures used in the cement-stabilized rammed earth (CSRE) compressive strength tests.

Table 1. Mineral compositions of soil mixtures given in percentages. The table also gives the percentage of water and CEM I $42.5 \mathrm{R}$ cement additions.

\begin{tabular}{|c|c|c|c|c|c|c|c|c|c|c|c|}
\hline $\begin{array}{l}\text { Mixture } \\
\text { symbol }\end{array}$ & 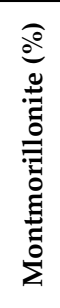 & 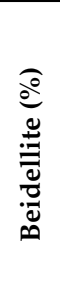 & 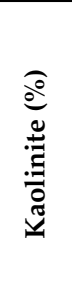 & 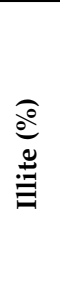 & 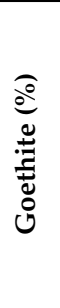 & 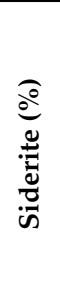 & $\begin{array}{l}\frac{0}{0} \\
\frac{0}{0} \\
\frac{0}{0} \\
0\end{array}$ & 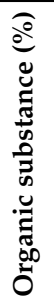 & 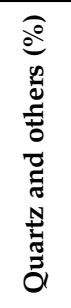 & 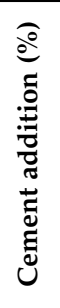 & $\begin{array}{c}\text { OMC } \\
(\%)\end{array}$ \\
\hline $\begin{array}{l}\text { LC II } 6 \% \\
\text { LC II } 9 \%\end{array}$ & 0.0 & 2.6 & 0.4 & 0.8 & 0.3 & 0.0 & 6.8 & 0.2 & 88.9 & $\begin{array}{l}6 \\
9\end{array}$ & 7 \\
\hline $\begin{array}{l}\text { LC VII 6\% } \\
\text { LC VII 9\% }\end{array}$ & 0.0 & 2.3 & 1.2 & 0.0 & 0.8 & 0.7 & 0.0 & 0.3 & 94.6 & $\begin{array}{l}6 \\
9\end{array}$ & 7 \\
\hline $\begin{array}{l}\text { LC XI 6\% } \\
\text { LC XI 9\% }\end{array}$ & 0.0 & 1.8 & 0.4 & 2.7 & 0.0 & 0.5 & 0.0 & 0.0 & 94.6 & $\begin{array}{l}6 \\
9\end{array}$ & 7 \\
\hline $\begin{array}{l}\text { MC III 6\% } \\
\text { MC III 9\% }\end{array}$ & 0.0 & 6.6 & 1.9 & 0.0 & 0.9 & 0.0 & 13.1 & 0.1 & 77.3 & $\begin{array}{l}6 \\
9\end{array}$ & 8 \\
\hline $\begin{array}{l}\text { MC IV 6\% } \\
\text { MC IV 9\% }\end{array}$ & 0.0 & 0.0 & 21.8 & 0.0 & 0.3 & 0.0 & 0.0 & 0.1 & 77.8 & $\begin{array}{l}6 \\
9\end{array}$ & 8 \\
\hline $\begin{array}{l}\text { MC V 6\% } \\
\text { MC V 9\% }\end{array}$ & 0.0 & 0.0 & 21.1 & 0.0 & 0.0 & 0.0 & 0.0 & 0.1 & 78.7 & $\begin{array}{l}6 \\
9\end{array}$ & 8 \\
\hline $\begin{array}{l}\text { MC X 6\% } \\
\text { MC X 9\% }\end{array}$ & 3.0 & 4.1 & 6.9 & 2.9 & 0.0 & 1.1 & 0.0 & 0.4 & 81.7 & $\begin{array}{l}6 \\
9\end{array}$ & 8 \\
\hline
\end{tabular}




\subsection{Preparation of Samples}

All CSRE samples were prepared at the construction materials laboratory (Warsaw University of Technology, Warsaw, Poland). In addition to the soil mixture properties listed in Section 3.1, the shape of the samples and the compaction technique also affect the compressive strength of the CSRE. Therefore, cubic $100 \times 100 \times 100 \mathrm{~mm}$ samples for compressive strength tests were formed as described in the work of Hall and Djerbib [36]. The shaping of the samples was carried out by ramming the moist soil-cement mixture in three equal layers. Each layer was compacted by freely lowering a $6.5 \mathrm{~kg}$ rammer from a height of $30 \mathrm{~cm}$ to the surface of the mixture. Samples were removed from steel molds after $24 \mathrm{~h}$. From the moment of compaction until the compressive strength test, the samples were cured in conditions of a temperature of $20^{\circ} \mathrm{C}\left( \pm 1^{\circ} \mathrm{C}\right)$ and relative humidity of $95 \%( \pm 2 \%)$. Ten samples were prepared for each of the 14 soil-cement mixtures.

Initially, samples were formed with a height of $105 \mathrm{~mm}$. The day before the planned compressive strength test, they were cut to a height of $100 \mathrm{~mm}$ (Figure 3). Thin sections to be examined using an SEM were made from the cut fragments of the samples.

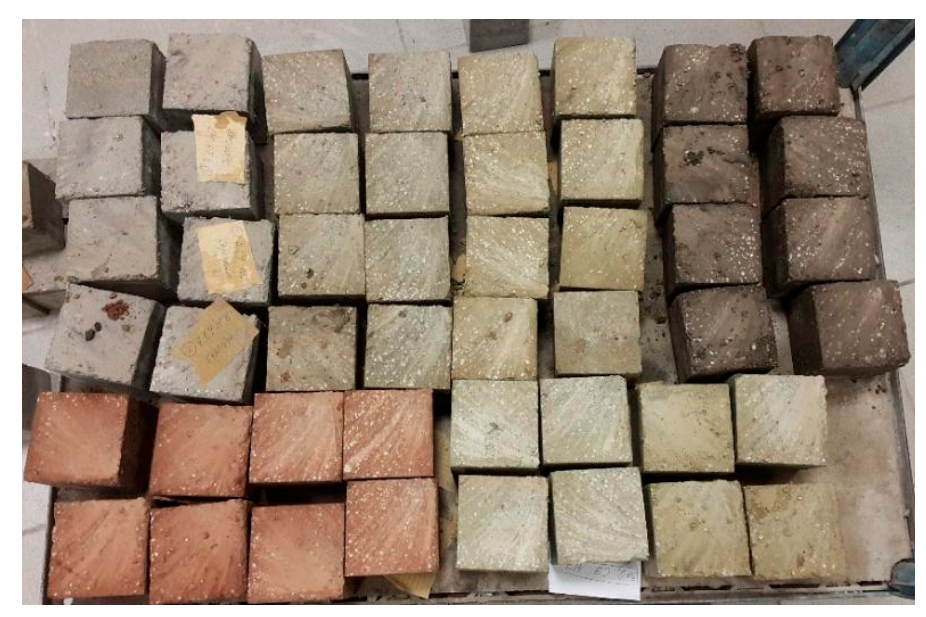

Figure 3. Part of CSRE samples on which the compressive strength tests were made.

\subsection{Methods}

\subsubsection{CSRE Compressive Strength Test}

CSRE retains the layer structure both in the monolithic wall and in molded samples. For this reason, the method of testing the compressive strength by loading the sample in the direction of its formation was considered representative. Tests on the compressive strength of CSRE samples were carried out in a testing machine with a measuring range of 0-3000 kN, characterized by a measurement error of less than $1 \%$.

The results of the median of compressive strength of each of 14 tested series are shown in Figure 4. Comparing the results of the LC ( $4 \%$ clay fraction) and MC ( $16 \%$ clay fraction) series, it can be seen that the particle size of the soil has a great impact on the CSRE compressive strength. As expected, differences were observed between the compressive strengths of samples with the same particle size and cement content and with different mineral composition. 


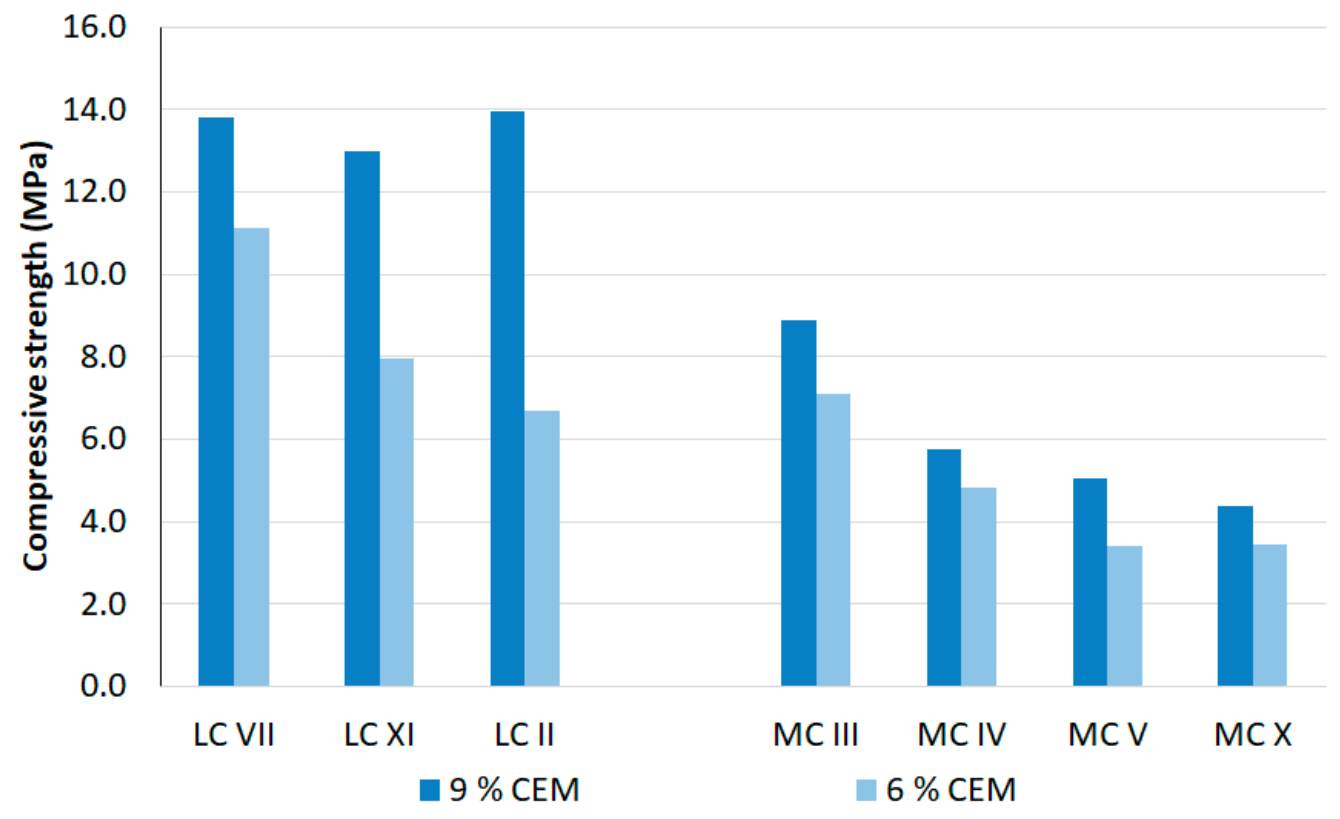

Figure 4. Compressive strength of the CSRE sample series (median).

\subsubsection{SEM Methodology}

To present the exact texture of the samples at the micro area, images were taken using an SEM. The magnifications used allowed the observation of small structures within the material matrix as well as small clusters of clay minerals.

Thin sections were sputtered with a thin layer of carbon coating $(\approx 20 \mathrm{~nm})$ to remove charging effects from the surface of the samples (Figure 5). The observations were carried out in a high vacuum on a Carl Zeiss SIGMA VP FE-SEM (Carl Zeiss Microscopy Ltd., Cambridge, the United Kingdom) with an accelerating voltage of $20 \mathrm{kV}$. The high voltage used reduced the impact of carbon coating and surface contamination on the quality of obtained backscattered electron (BSE) imaging. Thin sections were mapped under 150 $\times$ magnification, and acquired images had a relatively low resolution $(300 \times 225 \mathrm{px})$ as required for deep learning purposes. The area of the sample presented in each photo was approx. $2.112 \mathrm{~mm}^{2}$ (a rectangle of $1.258 \times 1.678 \mathrm{~mm}$ ). Some samples of the SEM images are presented in Figure 6.

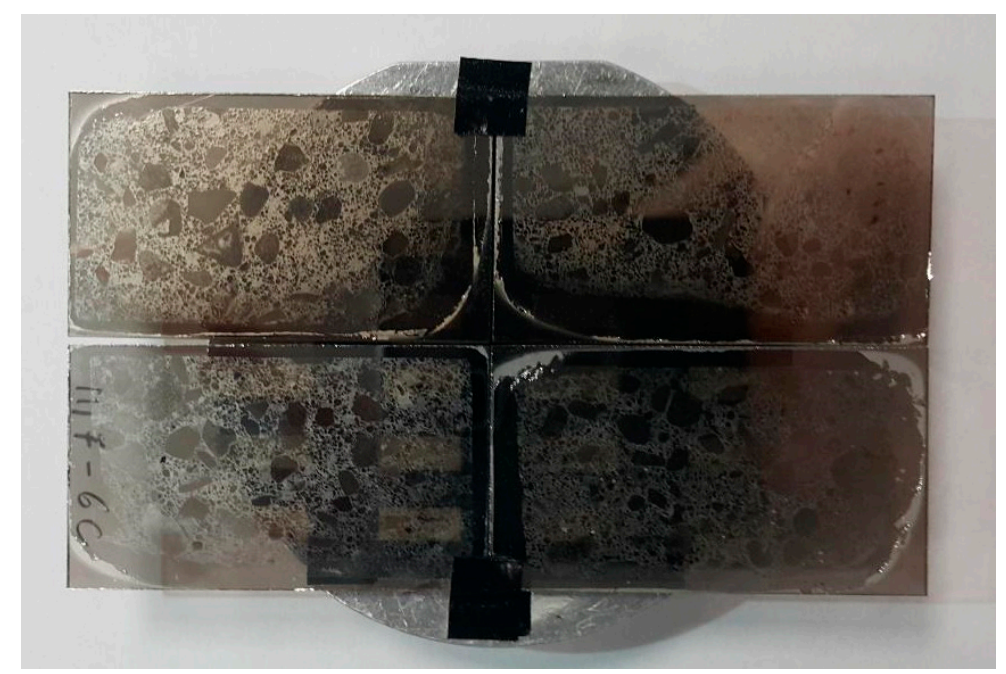

Figure 5. Carbon-sputtered thin sections of four different CSRE samples. 
CS

3.41

3.44

4.36

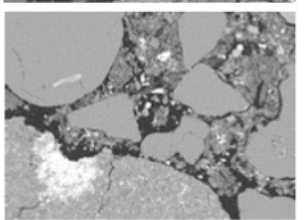

4.82

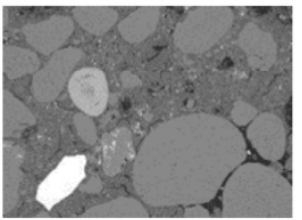

5.03

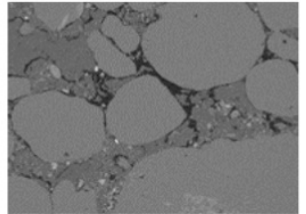

5.77

6.67
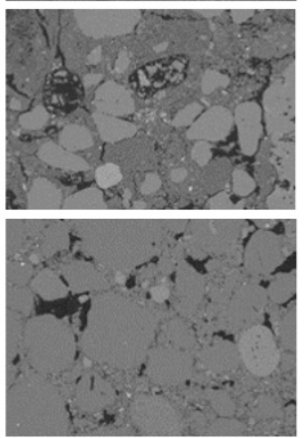

Example 2
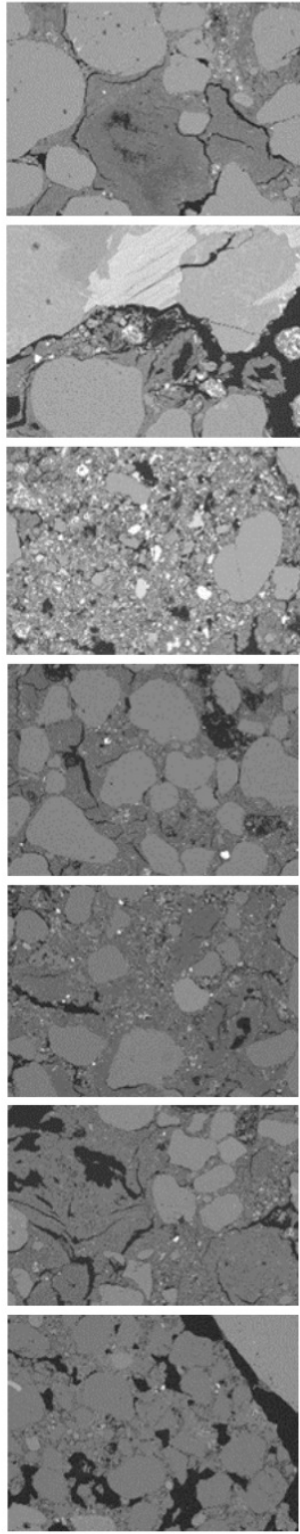

CS

7.11

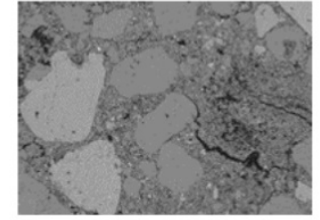

7.96

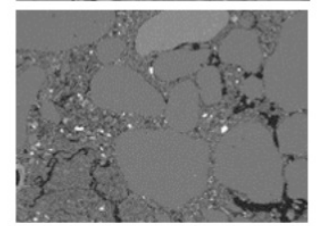

8.88
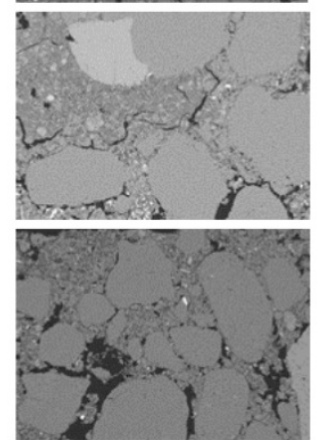

12.99
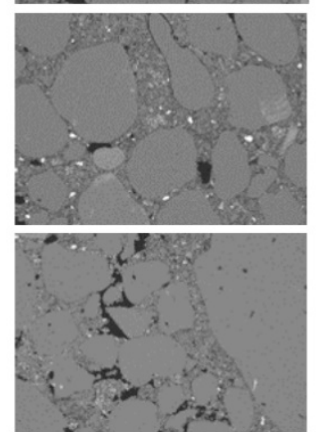

13.79

13.97

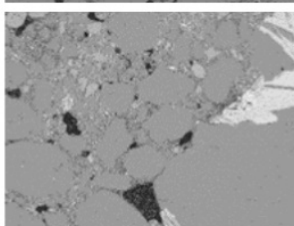

Example 2
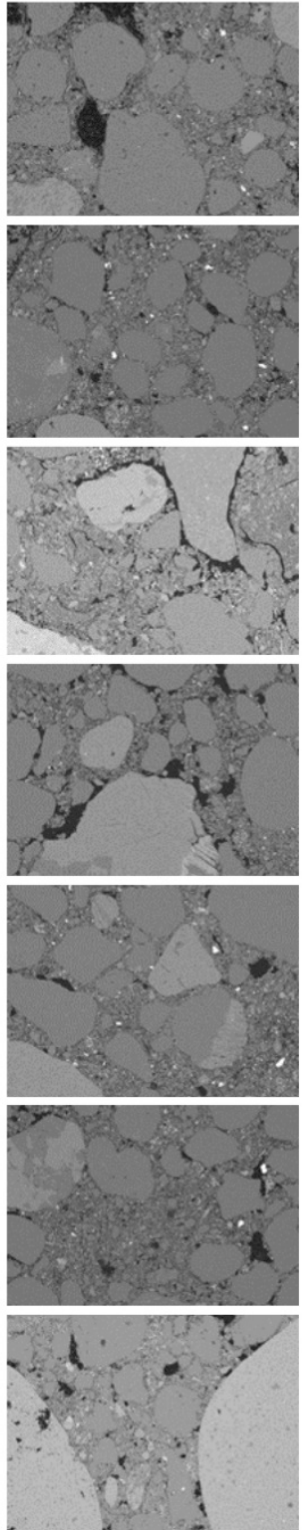

Figure 6. Random samples from the in-house SEM images database. CS - compressive strength (MPa).

\subsubsection{Deep Learning Methodology}

To predict the compressive strength of the CSRE samples from their SEM images, a deep convolutional neural network (DCNN) regression model was built. The architecture of the proposed model consisted of 24 layers, and the input images were resized and mapped to be $250 \times 250$. The other DCNN architecture details are described in Figure 7. The proposed neural network was trained using stochastic gradient descent with momentum (SGDM) optimizer built-in Matlab 2019a software (Mathworks, Natick, MA, USA), the mini-batch size assigned to be 128. 
2 Convolution

3 Batch Normalization

4 ReLU

$5 \quad$ Max Pooling

6 Convolution

7 Batch Normalization

8 ReLU

9 Max Pooling

10 Convolution

11 Batch Normalization

12 ReLU

13 Max Pooling

14 Convolution

15 Batch Normalization

16 ReLU

17 Max Pooling

18 Convolution

19 Batch Normalization

20 ReLU

21 Max Pooling

22 Dropout

23 Fully Connected

24 Regression Output
$250 \times 250 \times 3$ images with "zerocenter normalization" $165 \times 5$ convolutions with stride $\left[\begin{array}{ll}1 & 1\end{array}\right]$ and padding 'same' Batch normalization

ReLU

$5 \times 5$ max pooling with stride [ 33$]$ and padding [ $\left[\begin{array}{llll}0 & 0 & 0 & 0\end{array}\right]$ $325 \times 5$ convolutions with stride [1 1 1] and padding "same" Batch normalization

ReLU

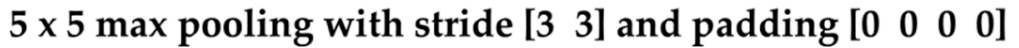
$643 \times 3$ convolutions with stride [1 1 ] and padding "same" Batch normalization

ReLU

$5 \times 5$ max pooling with stride [ [ 33$]$ and padding [ $\left[\begin{array}{llll}0 & 0 & 0 & 0\end{array}\right]$ $1283 \times 3$ convolutions with stride [1 1 1] and padding "same" Batch normalization

ReLU

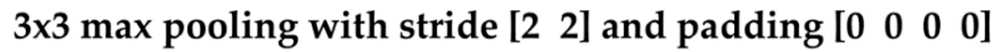
$5123 \times 3$ convolutions with stride [1 1 1] and padding "same" Batch normalization

\section{ReLU}

$3 \times 3$ max pooling with stride $\left[\begin{array}{ll}2 & 2\end{array}\right]$ and padding [ $\left[\begin{array}{llll}0 & 0 & 0 & 0\end{array}\right]$ $50 \%$ dropout

1 fully connected layer

Mean-squared-error

Figure 7. The architecture of the proposed deep convolutional neural network (DCNN) model.

4. Results and Discussion

To validate and test the proposed DCNN model, a 10-fold cross-validation approach was used. The training and validation process of the proposed model is presented in Figure 8.

As shown in Figure 8, the model-which is designed to be validated every 428 iterations to ensure that the network was not overfitting - starts to fit the data early in the process. The final root mean square error (RMSE) in the training process is approximately 1.39 .

To measure the prediction accuracy of the proposed DCNN, variable $\alpha$ was set to represent the gap between the predicted and the actual values. $\alpha$ is assumed to be an acceptable margin of error; for example, if $\alpha$ is set at 0.5 and the actual value of one sample is 1.7 , this prediction would be accepted as correct if the predicted value was in the range $1.7 \pm 0.5$. In this work, the prediction accuracy is measured using various $\alpha$ values. The prediction accuracy and its corresponding $\alpha$ value are presented in Table 2. The final prediction accuracy was calculated by averaging the accuracy of all folds. 

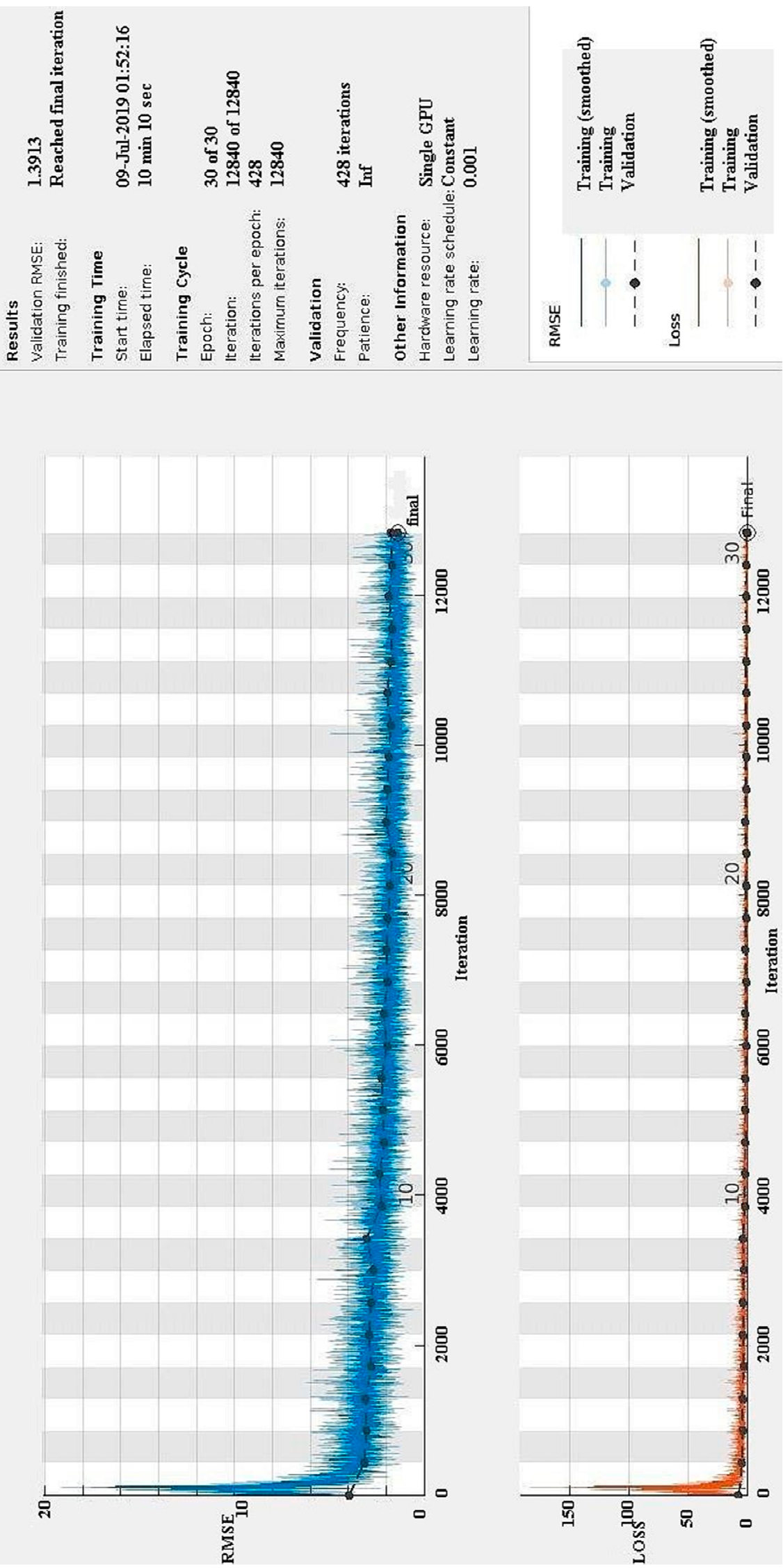

Figure 8. The training process of the proposed DCNN model. 
Table 2. Prediction accuracy of the proposed DCNN with their $\alpha$ values.

\begin{tabular}{cc}
\hline$\alpha$ & Prediction Accuracy \\
\hline 0.4 & 0.31 \\
0.6 & 0.46 \\
0.8 & 0.57 \\
1 & 0.64 \\
1.2 & 0.71 \\
1.4 & 0.75 \\
1.6 & 0.79 \\
1.8 & 0.81 \\
2 & 0.84 \\
\hline
\end{tabular}

As can be seen in Figure 9 and Table 2, the prediction accuracy starts to be acceptable (accuracy $>50 \%$ ) when $\alpha$ is assigned to be greater than 0.8 of the tested $\alpha$ values. Moreover, if it is recalled that the minimum compressive strength of the CSRE samples was 3.41 MPa and the maximum was $13.97 \mathrm{MPa}$, then $\alpha=2$ might be considered as an acceptable error threshold. Then a reasonable prediction accuracy of $84 \%$ is achieved. The accuracy of the prediction is proportional to the margin of error; however, the margin of error cannot be significantly increased to claim a higher prediction accuracy. Therefore, other measures such as the RMSE can be used to acquire a better understanding of the prediction system's performance [37].

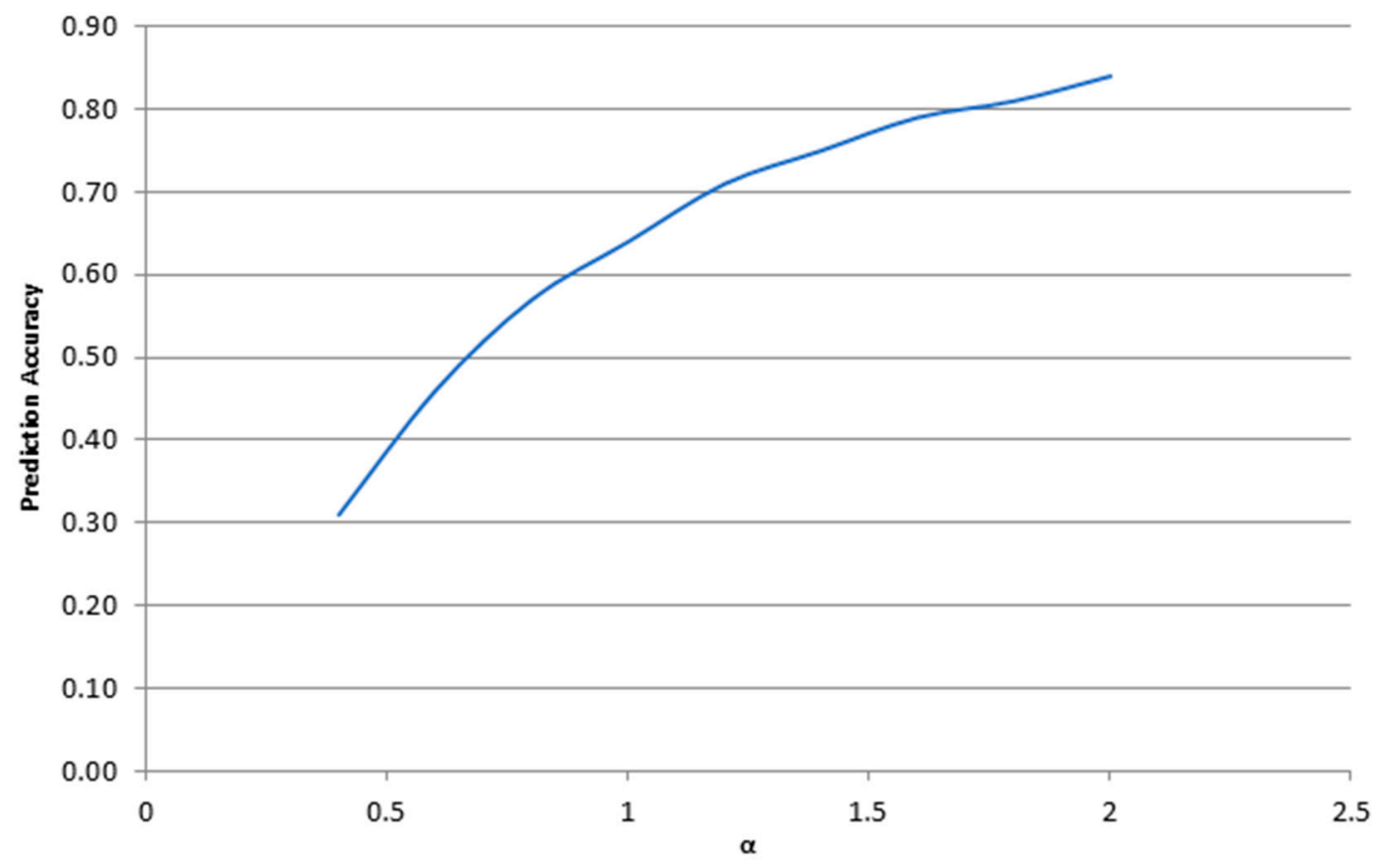

Figure 9. Prediction accuracy of the proposed DCNN as a function of $\alpha$ value.

Furthermore, to provide more information about the predictions of the proposed deep learning model, the covariance and correlation coefficient are calculated as results of the experiments. Table 3 demonstrates the correlation coefficient and the covariance for each fold separately.

As it can be observed in Table 3, the correlation is close to 0.9 , which statistically means that the predictions and the actual values have a very strong relationship between them. Moreover, the covariance shows that these sets of data have a positive relationship. 
Table 3. Correlation coefficient and covariance for each fold separately.

\begin{tabular}{ccc}
\hline Fold No. & Covariance & Correlation Coefficient \\
\hline Fold 1 & 8.742 & 0.857 \\
Fold 2 & 10.08 & 0.897 \\
Fold 3 & 9.588 & 0.914 \\
Fold 4 & 9.827 & 0.915 \\
Fold 5 & 9.385 & 0.853 \\
Fold 6 & 10.21 & 0.934 \\
Fold 7 & 9.411 & 0.910 \\
Fold 8 & 8.654 & 0.896 \\
Fold 9 & 8.622 & 0.890 \\
Fold 10 & 9.353 & 0.914 \\
\hline Average & 9.39 & 0.898 \\
\hline
\end{tabular}

In addition to the prediction, which is based on regression, the proposed DCNN can offer deep features that can be used by another regression method to obtain the prediction results. Two more regression methods are used: the random forest and linear regression features. In the case of calculating the prediction accuracy of the DCNN, the RMSE is one of the important measures that is usually used to measure the performance of a prediction system [37]. The number of deep features obtained by the proposed DCNN was quite large (4096 features); therefore, a principal component analysis (PCA) was used to reduce the number of features $[25,38,39]$, keeping $95 \%$ of the data variance to attain only 572 features. The average RMSE values (over 10 folds) of predicting the CSRE samples' compressive strength achieved by each method are presented in Table 4 .

Table 4. Average root mean square error (RMSE) of predicting the compressive strength of CSRE samples using the proposed DCNN and the deep features obtained.

\begin{tabular}{ccc}
\hline Method & No. of Features & RMSE (MPa) \\
\hline DCNN & 4096 & 1.5 \\
Random forest with PCA on the deep features & 572 & 3.1185 \\
Linear regression with PCA on the deep features & 572 & 2.5057 \\
\hline
\end{tabular}

It can be noticed (based on the results presented in Table 4) that the proposed DCNN with a regression model based on an artificial neural network, applied on all the obtained features (4096), outperforms the other regression models when compared. This is due to the use of all the deep features obtained from the DCNN, unlike the PCA, which reduces the quantity of the features. However, using a large number of features it is a time-consuming process.

To compare the proposed DCNN prediction model with other state-of-the-art traditional computer vision methods, the selection of the features from the SEM images was made with the use of the following algorithms: histogram of oriented gradients (HOG) [40], local binary pattern (LBP) [41], and scale-invariant feature transform (SIFT) [42]. The values of RMSE calculated for the compressive strength (of CSRE samples) predictions made with the use of these traditional features extraction methods are presented in Table 5 .

Table 5. RMSE of compressive strength (of CSRE samples) predictions achieved in a random forest and linear regression, fed with the features extracted traditionally from the SEM images.

\begin{tabular}{cccc}
\hline \multirow{2}{*}{ Method } & \multirow{2}{*}{ No. of Features } & \multicolumn{2}{c}{ RMSE (MPa) } \\
\cline { 3 - 4 } & & Random Forest & Linear Regression \\
\hline HOG & 72 & 3.2192 & 3.2217 \\
LBP & 10 & 2.4807 & 2.8518 \\
SIFT & 100 & 3.0682 & 4.6951 \\
\hline
\end{tabular}


It can be noticed (see Table 5) that none of the traditional methods could handle the prediction better than the proposed DCNN. This may be attributed to the representative power of the deep features obtained by the proposed model compared to that of the handcrafted low-level features (HOG, LBP, and SIFT). A similar effect is achieved by many researchers, e.g. in [43-45].

\section{Conclusions}

In addition to creating a new in-house SEM image database to be used for evaluating the model proposed in this paper, we provide a new deep learning model for predicting the compressive strength of CSRE based on SEM images using computer vision and deep learning. The comparative results of the experiments conducted on the SEM image database to predict the compressive strength of CSRE samples show that the proposed DCNN model outperforms other traditional computer vision methods, obtaining reasonable prediction results and comparatively low RMSE. Therefore, the method can be recommended for practical use as time, and cost-saving tool, as well as the environment protecting one, if applied instead of the current strength-testing machines.

Despite the reasonable performance of the proposed DCNN, the overall prediction accuracy process is still imperfect because it is the error threshold dependent. Such imperfect performance may be attributed to the number of SEM images used to train the deep features. This deficit can be alleviated by obtaining more SEM images of a higher number of CSRE samples to feed the DCNN. Higher prediction accuracy is expected then. Moreover, using the image enhancement techniques at a preprocessing stage may enhance the prediction results. It is considered to verify these statements in future analysis. Prospective future works will also include the use of DCNN to solve other problems described in [46-48]. It is expected to overcome the problem of prediction speed. It should increase with the use of more efficient indexing techniques, such as presented in [49-51].

Author Contributions: Conceptualization, H.A. and P.N.; methodology, A.S.T. and P.N.; software, A.S.T. and A.H.; validation, A.S.T., P.N. and A.H.; formal analysis, A.H. and K.A.; investigation, H.A., A.H., A.S.T., P.N. and J.K.; resources, P.N. and H.A.; data creation, P.N. and J.K.; writing-original draft preparation, A.S.T., P.N., K.A. and A.H.; writing—review and editing, A.H., K.A., and H.A.; visualization, P.N. and A.S.T.

Funding: This research received no external funding.

Acknowledgments: This research was supported by the Cryo-SEM laboratory, the National Multidisciplinary Laboratory of Functional Nanomaterials NanoFun project no. POIG.02.02.00-00-025/09 at the Faculty of Geology, University of Warsaw. A.S.T. would like to thank the Tempus Public Foundation for sponsoring his Ph.D. study. Also, A.S.T.'s work falls under the project EFOP-3.6.3-VEKOP-16-2017-00001 (Talent Management in Autonomous Vehicle Control Technologies) and is supported by the Hungarian Government, and co-financed by the European Social Fund. Moreover, the authors would like to thank the Institute for Computer Science and Control (SZTAKI) for providing an advanced server for training the proposed model.

Conflicts of Interest: The authors declare no conflict of interest.

\section{References}

1. Bre. Bre Group. 2008. Available online: https://www.bregroup.com/greenguide/ggelement.jsp? buildingType=Offices\&category=1019\&parent=6\&elementType=10166 (accessed on 23 September 2019).

2. Hall, M.R.; Swaney, W. European modern earth construction. In Modern Earth Buildings: Materials, Engineering, Construction and Applications; Hall, M.R., Lindsay, R., Krayenhoff, M., Eds.; Woodhead Pub Ltd.: Oxford, UK, 2012; pp. 650-687.

3. Reddy, B.V.; Kumar, P.P. Cement stabilised rammed earth. Part A: Compaction characteristics and physical properties of compacted cement stabilised soils. Mater. Struct. 2011, 44, 681-693. [CrossRef]

4. Anysz, H.; Narloch, P. Designing the composition of cement stabilized rammed earth using artificial neural networks. Materials 2019, 12, 1396. [CrossRef] [PubMed]

5. Ciancio, D.; Jaquin, P.; Walker, P. Advances on the assessment of soil suitability for rammed earth. Constr. Build. Mater. 2013, 42, 40-47. [CrossRef] 
6. Consoli, N.C.; Festugato, L.; da Rocha, C.G.; Cruz, R.C. Key parameters for strength control of rammed sand-cement mixtures: Influence of types of portland cement. Constr. Build. Mater. 2013, 49, 591-597. [CrossRef]

7. Lina, H.; Zhenga, S.; Lourençoa, S.; Jaquin, P. Characterization of coarse soils derived from igneous rocks for rammed earth. Eng. Geol. 2017, 228, 137-145. [CrossRef]

8. Narloch, P.L.; Woyciechowski, P.; Jęda, P. The influence of loam type and cement content on the compressive strength of rammed earth. Arch. Civ. Eng. 2015, 61, 73-88. [CrossRef]

9. Hall, M.; Allinson, D. Influence of cementitious binder content on moisture transport in stabilised earth materials analysed using 1-dimensional sharp wet front theory. Build. Environ. 2009, 44, 688-693. [CrossRef]

10. Hall, M.; Allinson, D. Assessing the moisture-content-dependent parameters of stabilised earth materials using the cyclic-response admittance method. Energy Build. 2008, 40, 2044-2051. [CrossRef]

11. Bui, Q.B. Assessing the rebound hammer test for rammed earth material. Sustainability 2017, 9, 1904. [CrossRef]

12. Bui, Q.B.; Morel, J.C.; Hans, S.; Walker, P. Effect of moisture content on the mechanical characteristics of rammed earth. Constr. Build. Mater. 2014, 54, 163-169. [CrossRef]

13. Beckett, C.; Ciancio, D. Effect of compaction water content on the strength of cement-stabilized rammed earth materials. Can. Geotech. J. 2014, 51, 583-590. [CrossRef]

14. Arrigoni, A.; Grillet, A.C.; Pelosato, R.; Dotelli, G.; Beckett, C.T.; Woloszyn, M.; Ciancio, D. Reduction of rammed earth's hygroscopic performance under stabilisation: An experimental investigation. Build. Environ. 2017, 115, 358-367. [CrossRef]

15. Bui, Q.B.; Morel, J.C. First Exploratory Study on the Ageing of Rammed Earth Material. Materials 2015, 8, 1-15. [CrossRef] [PubMed]

16. Bui, Q.B.; Morel, J.C.; Reddy, B.V.V.; Ghayad, W. Durability of rammed earth walls exposed for 20 years to natural weathering. Build. Environ. 2009, 44, 912-919. [CrossRef]

17. Narloch, P.L.; Lidner, M.; Kunicka, M.; Bielecki, M. Flexural tensile strength of construction elements made out of cement stabilized rammed earth. Procedia Eng. 2015, 111, 589-595. [CrossRef]

18. Narloch, P.L.; Woyciechowski, P.P.; Dmowska, E.; Halemba, K. Durability assessment of monolithic rammed earth walls. Arch. Civ. Eng. 2015, 61, 73-88. [CrossRef]

19. Lahoti, M.; Narang, P.; Tan, K.H.; Yang, E.H. Mix design factors and strength prediction of metakaolin-based geopolymer. Ceram. Int. 2017, 43, 11433-11441. [CrossRef]

20. Mirzahosseini, M.; Jiao, P.; Barri, K.; Riding, K.; Alavi, A.H. New machine learning prediction models for compressive strength of concrete modified with glass cullet. Eng. Comput. 2019, 36, 876-898. [CrossRef]

21. Qin, X.; Cui, S.; Liu, L.; Wang, P.; Wang, M.; Xin, J. Prediction of Mechanical Strength Based on Deep Learning Using the Scanning Electron Image of Microscopic Cemented Paste Backfill. Adv. Civ. Eng. 2018, 2018, 1-7. [CrossRef]

22. Drumetz, L.; Mura, M.D.; Meulenyzer, S.; Lombard, S.; Chanussot, J. Semiautomatic classification of cementitious materials using scanning electron microscope images. J. Electron. 2015, 24, 061109. [CrossRef]

23. Hughes, A.; Liu, Z.; Raftari, M.; Reeves, M.E. A workflow for characterizing nanoparticle monolayers for biosensors: Machine learning on real and artificial SEM images. Peerj Prepr. 2014. [CrossRef]

24. Gallagher, B.; Rever, M.; Loveland, D.; Mundhenk, T.N.; Beauchamp, B.; Robertson, E.; Han, T. Predicting Compressive Strength of Consolidated Molecular Solids Using Computer Vision; Deep Learning. arXiv 2019, arXiv:1906.02130.

25. Tarawneh, A.S.; Chetverikov, D.; Hassanat, A.B. Pilot Comparative Study of Different Deep Features for Palmprint Identification in Low-Quality Images. In Proceedings of the Ninth Hungarian Conference on Computer Graphics and Geometry, Budapest, Hungary, 10 March 2018.

26. Saritha, R.R.; Paul, V.; Kumar, P.G. Content based image retrieval using deep learning process. Clust. Comput. 2018, 22, 1-14. [CrossRef]

27. Tzelepi, M.; Tefas, A. Deep convolutional learning for Content Based Image Retrieval. Neurocomputing 2018, 275, 2467-2478. [CrossRef]

28. Cheng, G.; Zhou, P.; Han, J. Learning rotation-invariant convolutional neural networks for object detection in VHR optical remote sensing images. IEEE Trans. Geosci. Remote Sens. 2016, 54, 7405-7415. [CrossRef]

29. Lei, Z.; Yi, D.; Li, S.Z. Learning stacked image descriptor for face recognition. IEEE Trans. Circuits Syst. Video Technol. 2016, 26, 1685-1696. [CrossRef] 
30. Kappeler, A.; Yoo, S.; Dai, Q.; Katsaggelos, A.K. Video super-resolution with convolutional neural networks. IEEE Trans. Comput. Imaging 2016, 2, 109-122. [CrossRef]

31. Gao, S.; Zhang, Y.; Jia, K.; Lu, J.; Zhang, Y. Single sample face recognition via learning deep supervised autoencoders. IEEE Trans. Inf. Forensics Secur. 2015, 10, 2108-2118. [CrossRef]

32. Zhao, L.; Hu, Q.; Wang, W. Heterogeneous feature selection with multi-modal deep neural networks and sparse group lasso. IEEE Trans. Multimed. 2015, 17, 1936-1948. [CrossRef]

33. Liu, D.; Wang, Z.; Wen, B.; Yang, J.; Han, W.; Huang, T.S. Robust single image super-resolution via deep networks with sparse prior. IEEE Trans. Image Process. 2016, 25, 3194-3207. [CrossRef]

34. Dong, C.; Loy, C.C.; He, K.; Tang, X. Image super-resolution using deep convolutional networks. IEEE Trans. Pattern Anal. Mach. Intell. 2016, 38, 295-307. [CrossRef] [PubMed]

35. Goh, H.; Thome, N.; Cord, M.; Lim, J. Learning deep hierarchical visual feature coding. IEEE Trans. Neural Netw. Learn. Syst. 2014, 25, 2212-2225. [CrossRef] [PubMed]

36. Hall, M.; Djerbib, Y. Rammed earth sample production: Context, recommendations and consistency. Constr. Build. Mater. 2004, 18, 281-286. [CrossRef]

37. Lu, Y.; Tian, Z.; Peng, P.; Niu, J.; Li, W.; Zhang, H. GMM clustering for heating load patterns in-depth identification and prediction model accuracy improvement of district heating system. Energy Build. 2019, 190, 49-60. [CrossRef]

38. Hassanat, A.B.; Tarawneh, A.S. Fusion of Color and Statistic Features for Enhancing Content-Based Image Retrieval Systems. J. Theor. Appl. Inf. Technol. 2016, 88, 644-655.

39. Hassanat, A.B.A.; Prasath, V.B.S.; Al-kasassbeh, M.; Tarawneh, A.S.; Al-shamailh, A.J. Magnetic energy-based feature extraction for low-quality fingerprint images. Signal Image Video Process. 2018, 12, 1471-1478. [CrossRef]

40. Dalal, N.; Triggs, B. Histograms of Oriented Gradients for Human Detection; CVPR: Washington, DC, USA, 2005; pp. 886-893.

41. He, D.-C.; Wang, L. Texture Unit, Texture Spectrum, And Texture Analysis. IEEE Trans. Geosci. Remote Sens. 1990, 28, 509-512.

42. Lowe, D.G. Object recognition from local scale-invariant features. In Proceedings of the International Conference on Computer Vision, Kerkyra, Greece, 20 September 1999; pp. 1150-1157.

43. Wang, J.; Chen, Y.; Hao, S.; Peng, X.; Hu, J. Deep learning for sensor-based activity recognition: A survey. Pattern Recognit. Lett. 2019, 119, 3-11. [CrossRef]

44. Tarawneh, A.S.; Hassanat, A.B.; Celik, C.; Chetverikov, D.; Rahman, M.S.; Verma, C. Deep Face Image Retrieval: A Comparative Study with Dictionary Learning. In Proceedings of the 10th International Conference on Information and Communication Systems (ICICS), Irbid, Jordan, 11 June 2019; pp. 185-192.

45. Xia, Y.; Wulan, N.; Wang, K.; Zhang, H. Detecting atrial fibrillation by deep convolutional neural networks. Comput. Biol. Med. 2018, 93, 84-92. [CrossRef]

46. Hassanat, A.B.A. On Identifying Terrorists Using Their Victory Signs. Data Sci. J. 2018, 17, 1-13. [CrossRef]

47. Hassanat, A.B.; Btoush, E.; Abbadi, M.A.; Al-Mahadeen, B.M.; Al-Awadi, M.; Mseidein, K.I.; Almseden, A.M.; Tarawneh, A.S.; Alhasanat, M.B.; Prasath, V.S.; et al. Victory sign biometrie for terrorists identification: Preliminary results. In Proceedings of the 2017 8th International Conference on Information and Communication Systems (ICICS), Irbid, Jordan, 4-6 April 2017; pp. 182-187.

48. Hassanat, A.B.; Prasath, V.B.S.; Al-Mahadeen, B.M.; Alhasanat, S.M.M. Classification and gender recognition from veiled-faces. Int. J. Biom. 2017, 9, 347-364. [CrossRef]

49. Hassanat, A. Furthest-Pair-Based Decision Trees: Experimental Results on Big Data Classification. Information 2018, 9, 284. [CrossRef]

50. Hassanat, A. Furthest-pair-based binary search tree for speeding big data classification using k-nearest neighbors. Big Data 2018, 6, 225-235. [CrossRef]

51. Hassanat, A. Norm-Based Binary Search Trees for Speeding Up KNN Big Data Classification. Computers 2018, 7, 54. [CrossRef]

(C) 2019 by the authors. Licensee MDPI, Basel, Switzerland. This article is an open access article distributed under the terms and conditions of the Creative Commons Attribution (CC BY) license (http://creativecommons.org/licenses/by/4.0/). 